\title{
VERIFICATION OF SUBCRITICAL LIMITS IN ANSI/ANS-8.1-2014
}

\author{
Douglas G. Bowen ${ }^{1}$ and Travis M. Greene ${ }^{1}$ \\ Oak Ridge National Laboratory \\ PO Box 2008, MS 6170, Oak Ridge, TN 37831, USA \\ bowendg@,ornl.gov, greenetm@ornl.gov
}

\begin{abstract}
The ANSI/ANS-8.1 standard, "Safety Standard for Operations with Fissionable Materials Outside Reactors," has been available since 1964 as ASA N6.1-1964. In 1969, this standard was revised as ANSI N16.1-1969, "Nuclear Criticality Safety in Operations with Fissionable Materials Outside Reactors." This version of the standard includes a variety of subcritical limits (SCLs) for uniform aqueous solutions and metals containing fissile nuclides for ${ }^{233} \mathrm{U}$, ${ }^{235} \mathrm{U}$, and ${ }^{239} \mathrm{Pu}$. Furthermore, SCLs are also included for uranium-water lattices. In the 1983 version of ANSI/ANS-8.1 (a revision of ANSI N16.1-1975), the suite of SCLs in the standard expanded to include ${ }^{235} \mathrm{U}$ enrichment limits for homogeneous uranium-water mixtures and dry/damp oxides, uniform aqueous solutions of low-enriched uranium, and uniform aqueous mixtures of $\mathrm{Pu}\left(\mathrm{NO}_{3}\right)_{4}$ containing ${ }^{240} \mathrm{Pu}$, in addition to the SCLs included in ANSI N16.1-1969. The SCLs have changed little in subsequent revisions (ANSI/ANS-8.1-1998 and ANSI/ANS8.1-2014). The ANSI/ANS-8.1-2014 standard is currently being revised to include new SCLs (uranium metal and compounds with enrichments up to $20 \mathrm{wt} . \%{ }^{235} \mathrm{U}$ ) and possible updates to the current SCLs already in the standard, although these SCLs will not be available to the nuclear criticality safety community for a number of years. The bases for these SCLs were documented in journal articles such as Nuclear Science and Engineering, and the American Nuclear Society's meeting transactions; however, the bases were ambiguous enough that sites and regulators in the United States are reluctant to endorse them for safety purposes. The purpose of this paper is to present the results of a comparison study for the SCLs in the ANSI/ANS-8.1-2014 standard using modern codes and cross sections (SCALE/ENDF/BVIII) to provide some assurance about their quality (bias and bias uncertainty) for use in nuclear criticality safety applications.
\end{abstract}

KEYWORDS: subcritical limit, verification, standards

\footnotetext{
This manuscript has been authored by UT-Battelle, LLC, under contract DE-AC05-00OR22725 with the US Department of Energy (DOE). The US government retains and the publisher, by accepting the article for publication, acknowledges that the US government retains a nonexclusive, paid-up, irrevocable, worldwide license to publish or reproduce the published form of this manuscript, or allow others to do so, for US government purposes. DOE will provide public access to these results of federally sponsored research in accordance with the DOE Public Access Plan (http://energy.gov/downloads/doe-public-access-plan).
} 


\section{INTRODUCTION}

The ANSI/ANS-8.1 (ANS-8.1) [1] standard, "Nuclear Criticality Safety in Operations with Fissionable Materials Outside Reactors," has been available since 1964 as ASA N6.1-1964 [2] and provides a variety of subcritical limits (SCLs) for the handling, storing, processing, and transportation of fissionable material used for nuclear criticality safety (NCS) in process facilities. A 1969 revision of the ANS-8.1 standard, ANSI N16.1-1969, included a variety of SCLs for uniform aqueous solutions and metals containing fissile nuclides for ${ }^{233} \mathrm{U},{ }^{235} \mathrm{U}$, and ${ }^{239} \mathrm{Pu}$ along with uranium-water lattices [3].

The 1983 version of ANS-8.1 (a revision of ANSI N16.1-1975 [4]) was expanded to include SCLs of ${ }^{235} \mathrm{U}$ enrichment limits for homogeneous uranium-water mixtures and dry/damp oxides, uniform aqueous solution of low-enriched uranium, and uniform aqueous solutions of plutonium nitrate- $\mathrm{Pu}\left(\mathrm{NO}_{3}\right)_{4}-$ containing ${ }^{240} \mathrm{Pu}$ [5]. The SCLs in subsequent versions of the standard (ANSI/ANS-8.1-1998 [6] and ANSI/ANS-8.1-2014) have changed little; however, ANSI/ANS-8.1-2014 is currently being revised to include SCLs for uranium metal and compounds with enrichments up to $20 \mathrm{wt} \%{ }^{235} \mathrm{U}$. However, this revision will not be available to the NCS community for a number of years.

While the bases of these SCLs have been documented in journal articles such as Nuclear Science and Engineering and American Nuclear Society proceedings, they have remained ambiguous enough that regulators in the United States did not use or endorse them for safety purposes. This paper presents the results of a comparison study for SCLs listed in the ANS-8.1 standard using modern codes (SCALE) and cross sections (ENDF/B-VIII) to provide some assurance about their quality (bias and bias uncertainty) for use in NCS applications.

\section{SUBCRITICAL LIMIT COMPUTATIONS}

\subsection{General Approach}

Infinite and finite calculations were performed using KENO V.a in SCALE 6.2 [7] with ENDF/B-VIII [8] cross sections to compare to the ANS-8.1 SCLs in Tables 1-7 within the standard. For each table entry, parametric studies were developed and performed to determine the SCLs, which were then compared to the values specified in ANSI/ANS-8.1-2014. The parametric studies were developed based on the outcome of a 2005 ANS-8.1 working group (WG) meeting in which a calculational method was created [9]. This approach consisted of developing atom densities and performing criticality calculations over a range of parameter inputs which were first used by Argonne National Laboratory (ANL) in a previous implementation.

While the WG approach developed atom densities from material properties, the approach described here used atom densities calculated directly from SCALE based on the Pitzer method for calculating densities of electrolyte solutions $[10,11]$. Material entries in each table were calculated based on four geometries, with water reflection based on the desired output: (1) spheres for mass of fissile nuclide and volume of solution calculations, (2) infinite cylinders for diameters, (3) infinite slabs for thicknesses and areal densities of fissile nuclides, and (4) infinite medium cases for concentration of fissile nuclides and $\mathrm{H} / \mathrm{X}$ ratios of fissile nuclides (without water reflection). Each module assumes $30 \mathrm{~cm}$ of water reflectionessentially full water reflection - which has been assumed to bound neutron reflection from adjacent equipment, walls, personnel, etc. Specific geometries are described in more detail in the following sections, which address each table. 
The WG noted that past work over small multiplication ranges, such as $k_{e f f}=0.95$ to 1.0 , produced variations in $k_{\text {eff }}$ within a parameter value (e.g., dimension) that was linear, which could then be used in conjunction with a linear fit to interpolate to other $k_{\text {eff }}$ values, such as 0.98 . The ANL approach consisted of performing a standardized series of runs based on specific inputs to provide a good fit to establish confidence and to ensure that the dependence on the parameter dimension in question is linear. This study used the standardized format with $57 \mathrm{KENO}$ V.a runs, each with 4,000 neutrons per generation (NPG) and 250 generations (GEN) after skipping the first 50 generations (NSK) for source convergence. This is judged to be sufficient considering the simple geometric configurations modeled.

However, the first step in the calculational process involved determining the endpoints of the parameter variable that would result in the desired $k_{\text {eff }}$ range, which was chosen to correspond to the $k_{\text {eff }}$ values ranging from $\sim 0.94$ to $\sim 1.01$. This would ensure that the desired $k_{\text {eff }}$ value of 0.98 was sufficiently determined through the linear fit modeling process. The endpoint values were developed using a trial-anderror method based on the values found in the current standard or in other available references. While there are references to specific previous experiments that derived the current SCLs, it was often necessary to examine multiple variables to determine a single parameter variable. For example, the concentration of a solution was investigated before determining the parameter range for a geometric dimension. These investigations into endpoints were calculated by using the Sampler module in SCALE, which allows a user to perform multivariate parametric studies with variables containing a uniform distribution.

After the endpoints for a specific parameter range were determined, an additional Sampler script for KENO V.a was used to generate the 57 input files for each material/geometry configuration. Sampler allows for a single input file to execute the $57 \mathrm{KENO}$ V.a generated input files. All calculations were performed on the Romulus cluster at Oak Ridge National Laboratory (ORNL), with each node consisting of two 16-core AMD Opteron ${ }^{\circledR} 6378$ CPUs and 128 GB of memory. Upon completion of each parametric case, additional codes were developed to extract the $k_{\text {eff }}$ values, $1-\sigma$ uncertainties, and specific parametric variable values (such as radius or concentration of fissile nuclide) into a tabular text format that could be directly imported into Excel for analysis.

Using a standardized Excel template developed by ANL, output values were then used to plot parameters and calculate a linear fit so that linear correlation coefficients could be determined and any questionable values over the selected parameter range could be identified. Figure 1 shows an example of a plot of KENO V.a output data points, along with the uncertainty bands and a close-up view of the $k_{\text {eff }}$ value of 0.98 . These specific plots were used only to determine linearity and distribution of data, and they will not be presented here in this report. The Excel template also includes the equations used to determine the uncertainties at the three $k_{\text {eff }}$ values of $0.95,0.98$, and 1.00 for a given parameter value.

For example, at a given $k_{\text {eff }}$ value, the upper and lower $1-\sigma$ values (see Figure 1) are used to determine linear fit lines for that specific parameter, i.e., fissile mass, cylinder diameter, etc. These additional fit lines are then used to determine the $1-\sigma$ uncertainty values for the specific $k_{\text {eff }}$ values in question. The final $k_{\text {eff }}=0.98$ value which is then reported in the subsequent tables for SCL calculations is the calculated SCL determined from the linear fit model minus $3 * \sigma$ uncertainty, which is consistent with the ANL methodology. 


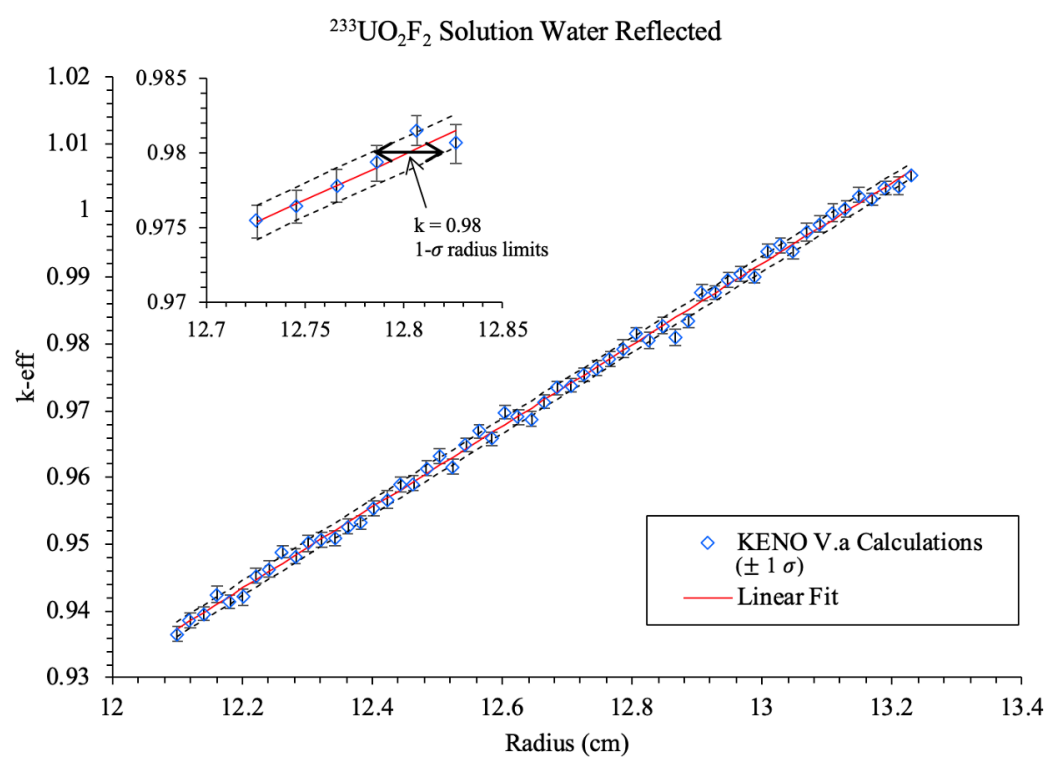

Figure 1. Example of Linear Fit and Uncertainty Determination.

\subsection{Specific Table Procedures}

ANS-8.1 provides single and multi-parameter limits to be used to support fissionable material operations being conducted outside of reactors, in places such as process facilities where fissionable materials are stored, handled, and transported. These SCLs are based on either a computation or a combination of a computation and experimental data. The values presented in the table were selected based on a consensus process within the ANS-8.1 WG and may be more restrictive than the computations or experimental data, as additional subcritical margin, less mass or smaller diameter may have been reflected in the actual limit provided. The following sections introduce each table in ANS-8.1 that contains SCLs. Tables listed by an Arabic number refer to specific tables in ANS-8.1, whereas those listed by a Roman numeral refer to tables generated for this paper.

Table 1 in ANS-8.1 provides single-parameter limits for uniform aqueous solutions of fissile nuclides which include ${ }^{233} \mathrm{U}$ - and ${ }^{235} \mathrm{U}$-uranyl fluoride $\left(\mathrm{UO}_{2} \mathrm{~F}_{2}\right)$, uranyl nitrate $\left(\mathrm{UO}_{2}\left(\mathrm{NO}_{3}\right)_{2}\right)$, and ${ }^{239} \mathrm{Pu}$-plutonium nitrate $\left(\mathrm{Pu}\left(\mathrm{NO}_{3}\right)_{4}\right)$ solutions. It is assumed that a uniform aqueous solution is maintained at a concentration that does not exceed those of the saturated solutions. The ${ }^{239} \mathrm{Pu}$ SCLs apply to configurations with mixtures of plutonium isotopes, assuming that the concentration of ${ }^{240} \mathrm{Pu}$ exceeds that of ${ }^{241} \mathrm{Pu}$, and provided that ${ }^{241} \mathrm{Pu}$ is considered to be ${ }^{239} \mathrm{Pu}$ in computing mass or concentration. For the calculations here, to simplify and bound the presence of all $\mathrm{Pu}$ isotopes, only ${ }^{239} \mathrm{Pu}$ is considered. These solutions were modeled having no excess acid $\left(0 \mathrm{M}\right.$ of $\mathrm{HF}$ or $\left.\mathrm{HNO}_{3}\right)$ and $100 \mathrm{wt} \%{ }^{233} \mathrm{U},{ }^{235} \mathrm{U}$, or ${ }^{239} \mathrm{Pu}$. These assumptions bound the presence of neutron absorbers that may be present in the solution. KENO V.a automatically calculates the densities of the solutions based on the concentration of fissile nuclide $(\mathrm{g} / \mathrm{L})$, isotopics, acid molarity, temperature, and volume fraction. Sampler was then run to sweep through the parameter endpoints found by the trial-and-error approach, with subsequent output data analyzed in Excel to determine the final $k_{\text {eff }}=0.98$ value reported in this paper. All geometries modeled included 30 $\mathrm{cm}$ of water reflection except for the infinite medium cases, which had mirrored boundaries along all faces. 
Table 2 provides SCLs for ${ }^{235} \mathrm{U}$ enriched compounds mixed homogenously with water without any limitations on mass or concentration. All inputs for this table were modeled as infinite medium cases by modeling a finite cube with mirror boundary conditions. Table 2 mentions that the enrichment limits for $\mathrm{UO}_{2}, \mathrm{UO}_{3}$, and $\mathrm{U}_{3} \mathrm{O}_{8}$ can be increased above the listed $\mathrm{SCL}$, from 0.96 to $3.2 \mathrm{wt} \%{ }^{235} \mathrm{U}$, if the homogeneous water content in the uranium oxide is limited to $1.5 \mathrm{wt} \%$ or less. This higher enrichment limit was not analyzed since Tables 4 and 5 also include an analysis of oxides at $1.5 \%$ water.

Table 3 provides SCLs for metallic units of ${ }^{235} U$ and ${ }^{239} \mathrm{Pu}$. All inputs were modeled as $100 \mathrm{wt} \%{ }^{233} \mathrm{U}$, ${ }^{235} \mathrm{U}$, or ${ }^{239} \mathrm{Pu}$, except for the parameter involving ${ }^{235} \mathrm{U}$ enrichment to bound all other uranium or plutonium isotopes that may be present. The maximum densities for which mass and dimension limits were valid as listed in the table were used for analysis in all modeling inputs. For example, all ${ }^{233} \mathrm{U}$ calculations were performed with the listed density of $18.65 \mathrm{~g} / \mathrm{cm}^{3},{ }^{235} \mathrm{U}$ with density $18.81 \mathrm{~g} / \mathrm{cm}^{3}$, and ${ }^{239} \mathrm{Pu}$ with density $19.82 \mathrm{~g} / \mathrm{cm}^{3}$. The values in this table are valid for metal units of these fissile nuclides that have no concave surfaces and for configurations with multiple pieces of fissile metals, assuming there are no interstitial moderating materials present. Other rules of applicability involve the presence of other uranium isotopes such as ${ }^{234} \mathrm{U},{ }^{236} \mathrm{U}$, or ${ }^{238} \mathrm{U}$. Rules can be bounded by the presence of ${ }^{233} \mathrm{U}$ or ${ }^{235} \mathrm{U}$ if ${ }^{234} \mathrm{U}$ is considered to be ${ }^{233} \mathrm{U}$ or ${ }^{235} \mathrm{U}$, respectively, in computing the fissile mass. Also, the ${ }^{239} \mathrm{Pu}$ SCLs apply to isotopic mixtures of plutonium, assuming the concentration of ${ }^{240} \mathrm{Pu}$ exceeds that of ${ }^{241} \mathrm{Pu}$ and all isotopes are considered to be ${ }^{239} \mathrm{Pu}$ in computing the fissile mass. The density SCLs may also be adjusted for isotopic composition.

Tables 4 and 5 provide single-parameter SCLs for uranium and plutonium oxides containing no more than $1.5 \%$ water by weight at full and half densities. Again, all inputs were modeled with $100 \mathrm{wt} \%{ }^{233} \mathrm{U}$, ${ }^{235} \mathrm{U}$, or ${ }^{239} \mathrm{Pu}$, as well as the maximum bulk densities for which the limits were valid, which included $1.5 \%$ water by weight. This meant, for example, that the density for ${ }^{233} \mathrm{UO}_{2}$ could vary between 10.75 and $9.38 \mathrm{~g} / \mathrm{cm}^{3}$ for full density and 5.38 and $4.69 \mathrm{~g} / \mathrm{cm}^{3}$ for half density, depending upon the water content in the oxides. However, the full $1.5 \%$ water by weight was used for all calculations, using the lower-end density values to consider the fact that most oxides are hygroscopic and contain some nominal water content. This resulted in KENO V.a inputs specifying a density, as well as a weight percent of $98.5 \%$ oxide and $1.5 \%$ water.

Table 6 provides multi-parameter SCLs $\left({ }^{235} \mathrm{U}\right.$ enrichment in addition to one of the parameters in the table, e.g., mass, cylinder diameter, slab thickness, etc.) for uniform aqueous solutions of low-enriched uranium in uranyl fluoride and uranyl nitrate varying from 2 to $10 \mathrm{wt} \%{ }^{235} \mathrm{U}$. All models were similar to those in Table 1 in terms of geometry and parameterization; however, $\mathrm{UO}_{2} \mathrm{~F}_{2}$ solutions contained $5 \mathrm{M} \mathrm{HF}$, and $\mathrm{UO}_{2}\left(\mathrm{NO}_{3}\right)_{2}$ solutions contained 2.5 $\mathrm{M} \mathrm{HNO}_{3}$ to be consistent with the assumptions in Section 6.2 of ANS8.1, "Concentrations of saturated solutions, which are here taken to be 5 molar for $\mathrm{UO}_{2} \mathrm{~F}_{2}$ solutions and 2.5 molar for $\mathrm{UO}_{2}\left(\mathrm{NO}_{3}\right)_{2}$ solutions..." Densities for the solutions were not specified and were generated directly through KENO V.a using the Pitzer method.

Table 7 provides multi-parameter SCLs $\left({ }^{240} \mathrm{Pu}\right.$ content of the Pu present and one of the parameters in the table) for uniform aqueous solutions of $\mathrm{Pu}\left(\mathrm{NO}_{3}\right)_{4}$ containing both ${ }^{240} \mathrm{Pu}$ and ${ }^{241} \mathrm{Pu}$ in varying amounts $(\geq 5$ $\mathrm{wt} \%{ }^{240} \mathrm{Pu}$ and $\leq 1 \mathrm{wt} \%{ }^{241} \mathrm{Pu}, \geq 15 \mathrm{wt} \%{ }^{240} \mathrm{Pu}$ and $\leq 6 \mathrm{wt} \%{ }^{241} \mathrm{Pu}$, and $\geq 25 \mathrm{wt} \%{ }^{240} \mathrm{Pu}$ and $\leq 15 \mathrm{wt} \%$ ${ }^{241} \mathrm{Pu}$ ). The minimum and maximum values for both ${ }^{240} \mathrm{Pu}$ and ${ }^{241} \mathrm{Pu}$ were used for all calculations. The amount of excess $\mathrm{HNO}_{3}$ present in the solution was not specified in the table, so a $0 \mathrm{M} \mathrm{Pu}\left(\mathrm{NO}_{3}\right)_{4}$ solution was used for all modeling inputs for parametric studies, as well as KENO V.a density calculations. The ANS-8.1 standard provides some applicability information for this limit table, such as the stipulation that any ${ }^{238} \mathrm{Pu}$ or ${ }^{242} \mathrm{Pu}$ present shall be omitted in computing the isotopic composition. 
Upon completion of the parameterization calculations, $k_{\text {eff }}=0.98$ values are provided for comparison purposes with those found in ANS-8.1 Tables 1-7. Tables I though VII presented below provide a summary of subcritical results for KENO V.a, based on results similar to those developed in Fig. 1 and the Excel template developed by the WG and ANL. All values generated in KENO V.a were based on a temperature of $300 \mathrm{~K}\left(26.85^{\circ} \mathrm{C}\right)$.

\section{RESULTS}

The ANS-8.1 SCLs have typically assumed a computational bias and bias uncertainty of about $2 \%$ in the $k_{\text {eff }}(0.98)$. Although it is difficult to verify [12-14], it is likely that the final SCLs chosen by past working groups were based on a combination of both computational and experimental data. The results presented here are those with a $k_{\text {eff }}$ value comparable to the legacy SCLs in the standard (0.98), which corresponds to a bias and bias uncertainty of about $2 \%$ in $k_{\text {eff. }}$. This computational effort is not a formal validation of this computational methodology but simply a comparison study based on an ANS-8.1-approved calculational methodology to compare calculations with modern radiation transport codes and cross sections to the legacy SCLs as a first step in the deriving new SCLs based on a formal validation effort.

The SCL KENO V.a $k_{\text {eff }}$ results for each table are compared to the corresponding $k_{\text {eff }}$ values of the ANS8.1 SCLs. For example, in Table I, the linear fit calculated SCL for the diameter of a cylinder of solution of ${ }^{235} \mathrm{UO}_{2} \mathrm{~F}_{2}$ was $13.6 \mathrm{~cm}$, and the current value listed in ANS- 8.1 is $13.7 \mathrm{~cm}$. This results in $k_{\text {eff }}$ values of $0.97665 \pm 0.00112$ and $0.98000 \pm 0.00110$, respectively, as calculated by KENO V.a (the linear fit calculated $k_{\text {eff }}$ from KENO V.a is based on the conservative formula: $k_{\text {eff }}-3^{*} \sigma$ ) with a $0.34 \%$ difference, which falls just outside of one standard deviation of the calculated ANS-8.1 value. This may suggest that the current SCL for the cylinder diameter for ${ }^{235} \mathrm{UO}_{2} \mathrm{~F}_{2}$ solution may be too high and should be lowered by one millimeter. The ANS-8.1 WG could review this information along with their own calculations to determine if an ANS-8.1 SCL value should be revised accordingly. The opposite is true for those calculated SCL values in all tables where the KENO V.a linear fit calculated values are higher than those listed in ANS-8.1, suggesting that current SCL values could be raised given the over-prediction in $k_{\text {eff }}$ as compared to the ANS-8.1 calculated values. For example, in Table IV below, the calculated linear fit value for the mass of fissile nuclide in ${ }^{235} \mathrm{UO}_{3}$ is $55.6 \mathrm{~kg}$ as compared to the ANS-8.1 value of $51.2 \mathrm{~kg}$. However, this large difference in mass only results in a difference in $k_{\text {eff }}$ of $1.77 \%(0.97705 \pm 0.00098$ and $0.96008 \pm 0.00090$, respectively). However, overall, comparison between the ANS-8.1 values and these computations should be performed with care. The SCL limits in ANS-8.1 were established in the 1960s with older codes and cross sections. As mentioned above, the SCL values in the standard were not solely based on calculational results but were consensus values based on both the computations and the availability of applicable experimental data. The ANS-8.1 WG may find it useful to reconsider the current SCLs based on the data here and other independent computations.

It is worth noting that all results generated for comparisons of Tables IV and V for oxides at full and half densities produced results that were significantly higher than those listed in ANS-8.1. The values listed in ANS-8.1 appear to be over-conservative given those generated by KENO V.a; however, these values remain bounding in current use but justify further investigations. Clark notes that calculations for values listed in ANS-8.1 for cylinder diameters and slabs in Tables 4 and 5 were derived using dry oxides since it is not practical to require a moisture content of $1.5 \%$ [14] for these elements. These changes along with current transport codes and updated libraries may be the cause for the increased KENO V.a values noted in Tables IV and V.

Keeping this in mind, based on the results presented in Tables I-VII below, linear fit calculations underpredicted SCLs by $37.5 \%$ (57 total) and over-predicted them by $62.5 \%$ (95 total). However, $53.3 \%$ of those under- or over-predictions only differed from the assumed ANS- $8.1 k_{\text {eff }}$ values by less than $1.00 \%$, 
meaning that either the linear fit SCLs were the same as ANS-8.1 values or were only slightly different, as evidenced by the one-millimeter difference in cylinder diameter noted above. Overall, $84.9 \%$ of calculated linear fit SCLs were within a 5.00\% difference of the calculated ANS-8.1 values. Of the remaining $15.3 \%$, large differences were noted in ${ }^{233} \mathrm{U}$ metals and oxides (Table III) at full and half densities (Tables IV and V), and low-enriched concentrations of ${ }^{235} \mathrm{UO}_{2}\left(\mathrm{NO}_{3}\right)_{2}$ solutions (Table VI).

While there are exceptions in every table, in general, highly enriched solutions $\left({ }^{233} \mathrm{U},{ }^{235} \mathrm{U}\right.$, and $\left.{ }^{239} \mathrm{Pu}\right)$ and metals that were calculated in KENO V.a using the linear fit model have SCLs similar to those found in ANS-8.1 (less than 5\% difference in $k_{\text {eff }}$ ), thus helping to further validate those particular limits for safety applications. On the other hand, oxides (particularly ${ }^{233} \mathrm{U}$ ) and $10 \mathrm{wt} \%{ }^{235} \mathrm{U}$ enriched solutions warrant further investigations given the large deviations from ANS-8.1 SCL values. The results of these calculations are likely a consequence of older computational methods and nuclear data.

Table I. Single-parameter SCLs for uniform aqueous solutions of fissile nuclides.

\begin{tabular}{|c|c|c|c|c|c|}
\hline \multirow{4}{*}{ Parameter } & \multicolumn{5}{|c|}{ SCL for fissile solute* } \\
\hline & ${ }^{233} \mathrm{UO}_{2} \mathrm{~F}_{2}$ & ${ }^{233} \mathrm{UO}_{2}\left(\mathrm{NO}_{3}\right)_{2}$ & ${ }^{235} \mathrm{UO}_{2} \mathbf{F}_{2}$ & ${ }^{235} \mathrm{UO}_{2}\left(\mathrm{NO}_{3}\right)_{2}$ & ${ }^{239} \mathrm{Pu}\left(\mathrm{NO}_{3}\right)_{4}$ \\
\hline & \multicolumn{5}{|c|}{ ANS-8.1 value } \\
\hline & \multicolumn{5}{|c|}{ KENO V.a value } \\
\hline \multirow{2}{*}{ Mass of fissile nuclide (kg) } & 0.54 & 0.55 & 0.76 & 0.78 & 0.48 \\
\hline & 0.52 & 0.54 & 0.73 & 0.75 & 0.49 \\
\hline \multirow{2}{*}{ Diameter of cylinder of solution $(\mathrm{cm})$} & 10.5 & 11.7 & 13.7 & 14.4 & 15.4 \\
\hline & 10.5 & 11.7 & 13.6 & 14.5 & 15.2 \\
\hline \multirow{2}{*}{ Thickness of slab of solution (cm) } & 2.5 & 3.1 & 4.4 & 4.9 & 5.5 \\
\hline & 2.5 & 3.1 & 4.5 & 5.1 & 5.4 \\
\hline \multirow{2}{*}{ Volume of solution $(\mathrm{L})$} & 2.8 & 3.6 & 5.5 & 6.2 & 7.3 \\
\hline & 2.8 & 3.7 & 5.4 & 6.6 & 7.3 \\
\hline \multirow{2}{*}{ Concentration of fissile nuclide $(\mathrm{g} / \mathrm{L})$} & 10.8 & 10.8 & 11.6 & 11.6 & 7.3 \\
\hline & 10.8 & 10.9 & 11.6 & 11.7 & 7.0 \\
\hline \multirow{2}{*}{$\begin{array}{l}\text { Atomic ratio of hydrogen to fissile } \\
\text { nuclide }\end{array}$} & 2,390 & 2,390 & 2,250 & 2,250 & 3,630 \\
\hline & 2,380 & 2,369 & 2,235 & 2,224 & 3,773 \\
\hline \multirow{2}{*}{ Areal density of fissile nuclide $\left(\mathrm{g} / \mathrm{cm}^{3}\right)$} & 0.35 & 0.35 & 0.40 & 0.40 & 0.25 \\
\hline & 0.35 & 0.35 & 0.40 & 0.41 & 0.25 \\
\hline
\end{tabular}

Table II. ${ }^{235} \mathrm{U}$ enrichment SCLs for uranium mixed homogenously with water.

\begin{tabular}{|l|c|c|}
\hline \multirow{2}{*}{ Compound } & \multicolumn{2}{|c|}{ SCLs (wt\% $\left.{ }^{\mathbf{2 3 5}} \mathbf{U}\right)$} \\
\cline { 2 - 3 } & ANS-8.1 & KENO V.a \\
\hline Uranium metal & 0.93 & 0.92 \\
\hline $\mathrm{UO}_{2}, \mathrm{U}_{3} \mathrm{O}_{8}$, or $\mathrm{UO}_{3}$ & 0.96 & $1.01,0.96,0.96$ \\
\hline $\mathrm{UO}_{2}\left(\mathrm{NO}_{3}\right)_{2}$ & 1.96 & 1.94 \\
\hline
\end{tabular}


Table III. Single-parameter limits for metal units.

\begin{tabular}{|c|c|c|c|c|c|c|}
\hline \multirow{3}{*}{ Parameter } & \multicolumn{6}{|c|}{ SCLs for } \\
\hline & ${ }^{233} \mathbf{U}$ & ${ }^{235} \mathbf{U}$ & ${ }^{239} \mathbf{P u}$ & ${ }^{233} \mathbf{U}$ & ${ }^{235} \mathbf{U}$ & ${ }^{239} \mathbf{P u}$ \\
\hline & \multicolumn{3}{|c|}{ ANS-8.1 } & \multicolumn{3}{|c|}{ KENO V.a } \\
\hline Mass of fissile nuclide $(\mathrm{kg})$ & 6.0 & 20.1 & 5.0 & 6.6 & 19.6 & 5.0 \\
\hline Cylinder diameter $(\mathrm{cm})$ & 4.5 & 7.3 & 4.4 & 4.8 & 7.3 & 4.4 \\
\hline Slab thickness $(\mathrm{cm})$ & 0.38 & 1.3 & 0.65 & 0.51 & 1.5 & 0.70 \\
\hline Uranium enrichment $\left(\mathrm{wt} \%{ }^{235} \mathrm{U}\right)$ & - & 5.0 & - & - & 5.3 & - \\
\hline $\begin{array}{l}\text { Maximum density for which mass } \\
\text { and dimension limits are valid } \\
\left(\mathrm{g} / \mathrm{cm}^{3}\right)\end{array}$ & 18.65 & 18.81 & 19.82 & 18.65 & 18.81 & 19.82 \\
\hline
\end{tabular}

Table IV. Single-parameter SCLs for oxides containing no more than $1.5 \%$ water by weight at full density.

\begin{tabular}{|c|c|c|c|c|c|c|c|}
\hline \multirow{3}{*}{ Parameter } & ${ }^{233} \mathrm{UO}_{2}$ & ${ }^{233} \mathrm{U}_{3} \mathrm{O}_{8}$ & ${ }^{233} \mathrm{UO}_{3}$ & ${ }^{235} \mathrm{UO}_{2}$ & ${ }^{235} \mathrm{U}_{3} \mathrm{O}_{8}$ & ${ }^{235} \mathrm{UO}_{3}$ & ${ }^{239} \mathrm{PuO}_{2}$ \\
\hline & \multicolumn{7}{|c|}{ ANS-8.1 } \\
\hline & \multicolumn{7}{|c|}{ KENO V.a } \\
\hline \multirow{2}{*}{ Mass of fissile nuclide $(\mathrm{kg})$} & 10.1 & 13.4 & 15.2 & 32.3 & 44.0 & 51.2 & 10.2 \\
\hline & 12.5 & 17.0 & 19.6 & 34.4 & 47.5 & 55.6 & 11.6 \\
\hline \multirow{2}{*}{ Mass of oxide (kg) } & 11.7 & 16.0 & 18.7 & 37.2 & 52.8 & 62.6 & 11.5 \\
\hline & 14.5 & 20.4 & 24.0 & 39.6 & 57.0 & 68.0 & 13.3 \\
\hline \multirow{2}{*}{ Cylinder diameter $(\mathrm{cm})$} & 7.2 & 9.0 & 9.9 & 11.6 & 14.6 & 16.2 & 7.2 \\
\hline & 8.2 & 10.0 & 11.0 & 12.2 & 15.1 & 16.7 & 8.0 \\
\hline \multirow{2}{*}{ Slab thickness (cm) } & 0.8 & 1.1 & 1.3 & 2.9 & 4.0 & 4.6 & 1.4 \\
\hline & 1.2 & 1.6 & 1.9 & 3.2 & 4.3 & 4.9 & 1.7 \\
\hline $\begin{array}{l}\text { Maximum bulk density for } \\
\text { which limits are valid } \\
\left(\mathrm{g} / \mathrm{cm}^{3}\right)\end{array}$ & $9.38^{*}$ & 7.36 & 6.56 & 9.44 & 7.41 & 6.60 & 9.92 \\
\hline
\end{tabular}

*Maximum bulk density was assumed (1.5 wt\% water) from Ref. 1, Table 4.

Table V. Single-parameter SCLs for oxides containing no more than $1.5 \%$ water by weight at half density.

\begin{tabular}{|c|c|c|c|c|c|c|c|}
\hline \multirow{3}{*}{ Parameter } & ${ }^{233} \mathrm{UO}_{2}$ & ${ }^{233} \mathrm{U}_{3} \mathrm{O}_{8}$ & ${ }^{233} \mathrm{UO}_{3}$ & ${ }^{235} \mathrm{UO}_{2}$ & ${ }^{235} \mathrm{U}_{3} \mathrm{O}_{8}$ & ${ }^{235} \mathrm{UO}_{3}$ & ${ }^{239} \mathrm{PuO}_{2}$ \\
\hline & \multicolumn{7}{|c|}{ ANS-8.1 } \\
\hline & \multicolumn{7}{|c|}{ KENO V.a } \\
\hline \multirow{2}{*}{$\begin{array}{l}\text { Mass of fissile nuclide } \\
(\mathrm{kg})\end{array}$} & 23.4 & 30.5 & 34.7 & 88 & 122 & 142 & 27 \\
\hline & 30.6 & 41.0 & 47.1 & 95 & 133 & 156 & 31 \\
\hline \multirow{2}{*}{ Mass of oxide $(\mathrm{kg})$} & 27.0 & 36.6 & 42.4 & 102 & 146 & 174 & 30 \\
\hline & 35.3 & 49.2 & 57.7 & 110 & 160 & 191 & 36 \\
\hline \multirow{2}{*}{ Cylinder diameter $(\mathrm{cm})$} & 11.9 & 14.8 & 16.3 & 20.4 & 26.0 & 28.8 & 12.6 \\
\hline & 13.8 & 16.8 & 18.5 & 21.6 & 26.8 & 29.7 & 14.0 \\
\hline \multirow[t]{2}{*}{ Slab thickness $(\mathrm{cm})$} & 1.6 & 2.2 & 2.6 & 5.8 & 8.0 & 9.3 & 2.8 \\
\hline & 2.4 & 3.2 & 3.7 & 6.4 & 8.5 & 9.8 & 3.4 \\
\hline $\begin{array}{l}\text { Maximum bulk density } \\
\text { for which limits are valid } \\
\left(\mathrm{g} / \mathrm{cm}^{3}\right)\end{array}$ & $4.69^{+}$ & 3.68 & 3.28 & 4.72 & 3.705 & 3.30 & 4.96 \\
\hline
\end{tabular}

+The maximum bulk densities are assumed to be half those listed in Table IV, which is consistent with bulk densities from Ref. 1, Table 5. 
Table VI. SCLs for uniform aqueous solutions of low-enriched uranium.

\begin{tabular}{|c|c|c|c|c|c|}
\hline \multirow{3}{*}{ Parameter } & \multirow{3}{*}{$\begin{array}{l}\text { Enrichment } \\
\left(\mathbf{w t} \%{ }^{235} U\right)\end{array}$} & \multicolumn{4}{|c|}{ SCLs } \\
\hline & & $\mathrm{UO}_{2} \mathbf{F}_{2}$ & $\mathrm{UO}_{2}\left(\mathrm{NO}_{3}\right)_{2}$ & $\mathrm{UO}_{2} \mathbf{F}_{2}$ & $\mathrm{UO}_{2}\left(\mathrm{NO}_{3}\right)_{2}$ \\
\hline & & \multicolumn{2}{|c|}{ ANS-8.1 } & \multicolumn{2}{|c|}{ KENO V.a } \\
\hline \multirow{5}{*}{ Mass $\left(\mathrm{kg}^{235} \mathrm{U}\right)$} & 10.0 & 1.07 & 1.47 & 1.18 & 1.99 \\
\hline & 5.0 & 1.64 & 3.30 & 1.61 & 4.54 \\
\hline & 4.0 & 1.98 & 6.50 & 1.95 & 7.27 \\
\hline & 3.0 & 2.75 & - & 2.73 & - \\
\hline & 2.0 & 8.00 & - & 8.07 & - \\
\hline \multirow{5}{*}{ Cylinder diameter $(\mathrm{cm})$} & 10.0 & 20.1 & 25.2 & 20.1 & 27.6 \\
\hline & 5.0 & 26.6 & 42.7 & 26.5 & 42.2 \\
\hline & 4.0 & 30.2 & 58.6 & 30.0 & 57.6 \\
\hline & 3.0 & 37.4 & - & 37.2 & - \\
\hline & 2.0 & 63.0 & - & 62.5 & - \\
\hline \multirow{5}{*}{ Slab thickness $(\mathrm{cm})$} & 10.0 & 8.3 & 11.9 & 8.3 & 13.3 \\
\hline & 5.0 & 12.6 & 23.4 & 12.5 & 23.3 \\
\hline & 4.0 & 15.1 & 33.7 & 15.0 & 33.1 \\
\hline & 3.0 & 20.0 & - & 19.9 & - \\
\hline & 2.0 & 36.5 & - & 36.3 & - \\
\hline \multirow{5}{*}{ Volume (L) } & 10.0 & 14.8 & 26.7 & 14.7 & 34.5 \\
\hline & 5.0 & 30.6 & 111.0 & 30.2 & 105.8 \\
\hline & 4.0 & 42.7 & 273.0 & 42.0 & 255.3 \\
\hline & 3.0 & 77.0 & - & 76.1 & - \\
\hline & 2.0 & 340.0 & - & 335.7 & - \\
\hline \multirow{7}{*}{ Concentration (g U/L) } & 10.0 & 123.0 & 128.0 & 123.4 & 142.4 \\
\hline & 5.0 & 261.0 & 283.0 & 261.3 & 320.4 \\
\hline & 4.0 & 335.0 & 375.0 & 335.5 & 426.8 \\
\hline & 3.0 & 470.0 & - & 467.7 & - \\
\hline & 2.9 & - & $594.9^{*}$ & - & $594.9 * * *$ \\
\hline & 2.0 & 770.0 & - & 789.1 & - \\
\hline & 1.45 & $1,190.0^{*}$ & - & $1,190.0 * *$ & - \\
\hline
\end{tabular}


Table VII. SCLs for uniform aqueous solutions of $\mathrm{Pu}\left(\mathrm{NO}_{3}\right)_{4}$ containing ${ }^{240} \mathrm{Pu}$.

\begin{tabular}{|c|c|c|c|c|c|c|}
\hline \multirow{3}{*}{ Parameter } & \multicolumn{6}{|c|}{ SCLs } \\
\hline & \multicolumn{2}{|c|}{$\begin{array}{l}\geq 5 \mathrm{wt} \%{ }^{240} \mathrm{Pu} \\
\leq 1 \mathrm{wt} \%{ }^{241} \mathrm{Pu}\end{array}$} & \multicolumn{2}{|c|}{$\begin{array}{l}\geq 15 \mathrm{wt}^{\circ} \%{ }^{240} \mathrm{Pu} \\
\leq 6 \mathrm{wt} \%{ }^{241} \mathrm{Pu}\end{array}$} & \multicolumn{2}{|c|}{$\begin{array}{l}\geq 25 \mathrm{wt}^{\circ} \%{ }^{240} \mathrm{Pu} \\
\leq 15 \mathrm{wt} \%{ }^{241} \mathrm{Pu}\end{array}$} \\
\hline & ANS-8.1 & KENO V.a & ANS-8.1 & KENO V.a & ANS-8.1 & KENO V.a \\
\hline Mass (kg Pu) & 0.57 & 0.58 & 0.78 & 0.81 & 1.02 & 1.12 \\
\hline Cylinder diameter $(\mathrm{cm})$ & 17.4 & 17.3 & 19.5 & 19.6 & 21.3 & 21.5 \\
\hline Slab thickness $(\mathrm{cm})$ & 6.7 & 6.7 & 8.0 & 8.1 & 9.2 & 9.3 \\
\hline Volume (L) & 10.0 & 10.0 & 13.6 & 13.9 & 17.2 & 17.8 \\
\hline Concentration $(\mathrm{g} \mathrm{Pu} / \mathrm{L})$ & 7.8 & 7.5 & 8.9 & 8.6 & 10.2 & 9.9 \\
\hline $\mathrm{H} / \mathrm{Pu}$ & 3,400 & 3,516 & 2,980 & 3,057 & 2,600 & 2,669 \\
\hline Areal density $\left(\mathrm{g} \mathrm{Pu} / \mathrm{cm}^{2}\right)$ & 0.28 & 0.28 & 0.34 & 0.34 & 0.4 & 0.4 \\
\hline
\end{tabular}

\section{CONCLUSIONS}

The calculations presented in this paper were performed to conduct a comparison study of the SCLs in ANS-8.1 with new calculations performed with SCALE using modern ENDF/B-VIII neutron cross sections. The primary motivation for conducting this study was the reluctance of the US regulators to endorse the ANS-8.1 SCLs for NCS use. Although the ANS-8.1 WG had proposed performing these calculations, the process would have taken a number of years to complete. However, the ANS-8.1 WG did develop a methodology to calculate new SCL values. The results shown in Tables I-VII indicate good agreement in many cases with the majority of the calculations, either over- or under-predicting the ANS8.1 SCL values by less than $1.0 \%$. Overall, $84.9 \%$ of calculated linear fit SCLs were within a $5.00 \%$ difference of the calculated ANS-8.1 values. Of the remaining $15.3 \%$, large differences were noted in ${ }^{233} \mathrm{U}$ metals (Table III) and oxides at full and half densities (Tables IV and V), and low-enriched concentrations of ${ }^{235} \mathrm{UO}_{2}\left(\mathrm{NO}_{3}\right)_{2}$ solutions (Table VI). These results can be used by the ANS- $8.1 \mathrm{WG}$ to compare with those in ANS-8.1 to inform potential revision of the SCLs in the next iteration of the standard.

\section{ACKNOWLEDGMENTS}

This work is supported by the United States Department of Energy/National Nuclear Security Administration, Nuclear Safety Research and Development Program (DOE/NNSA NA-511).

\section{REFERENCES}

1. ANSI/ANS-8.1-2014, Nuclear Criticality Safety in Operations with Fissionable Materials Outside Reactors American Nuclear Society (2014).

2. N6.1-1964, A., Safety Standard for Operations with Fissionable Materials Outside Reactors. American Nuclear Society and The American Society of Mechanical Engineers (1964).

3. N16.1-1969, Nuclear Criticality Safety in Operations with Fissionable Materials Outside Reactors. American Nuclear Society (1969).

4. N16.1-1975/ANS-8.1, Nuclear Criticality Safety in Operations with Fissionable Materials Outside Reactors. American Nuclear Society (1975).

5. ANSI/ANS-8.1-1983, Nuclear Criticality Safety in Operations with Fissionable Materials Outside Reactors. American Nuclear Society (1983). 
6. ANSI/ANS-8.1-1998, Nuclear Criticality Safety in Operations with Fissionable Materials Outside Reactors. American Nuclear Society (1998).

7. SCALE Code System, M.A. Jessee and B.T Rearden, Editors. Oak Ridge National Laboratory: Oak Ridge, Tennessee. p. 2747 (2017).

8. D.A. Brown et al., "ENDF/B-VIII. 0: The 8th Major Release of the Nuclear Reaction Data Library with CIELO-Project Cross Sections, New Standards and Thermal Scattering Data." Nuclear Data Sheets. 148: pp. 1-142 (2018).

9. A.-W Group, ANS-8.1 Calculations-2005: Argonne National Laboratory (ANL) Approach and Methodology (2005).

10. C.F. Weber and C.M. Hopper, Application of the Pitzer Method for Modeling Densities of Actinide Solutions in the SCALE Code System. Nuclear Technology, 153(1): p. 1-8 (2006).

11. S.E. Parkey, K.R.E., and C. F. Weber, "Comparison of Uranyl Nitrate Solution Modeling Methods," in Proc. Nuclear Criticality Safety Division Topl. Mtg. Knoxville, TN (2005).

12. H. Clark, H., "Subcritical Limits for Plutonium Systems". Nuclear Science and Engineering. 79(1): pp. 65-84 (1981).

13. H. Clark, "Subcritical Limits for Uranium-233 U Systems." Nuclear Science and Engineering. 81 (1982).

14. H.K. Clark, "Subcritical limits for Uranium-235 Systems." Nuclear Science and Engineering. 81(3): pp. 351-378 (1982). 